\title{
Treatment of Intracranial Atherosclerotic Disease with a Balloon- Expandable Paclitaxel Eluting Stent
}

\author{
Procedural Safety, Efficacy and Mid-Term Patency
}

\author{
Z. Vajda $\cdot$ M. Aguilar · T. Göhringer $\cdot$ \\ D. Horváth-Rizea $\cdot$ H. Bäzner $\cdot$ H. Henkes
}

Received: 2 August 2011 / Accepted: 16 December 2011 / Published online: 18 January 2012

(C) The Author(s) 2011. This article is published with open access at Springerlink.com

\begin{abstract}
Purpose Procedural safety and high rates of in-stent recurrent stenotic lesions (ISR) remain a concern in the endovascular treatment of intracranial atherosclerotic disease (ICAD). In the present study technical feasibility, safety and efficacy of the paclitaxel eluting balloon-expandable coronary stent Coroflex ${ }^{\circledR}$ Please was assessed in the treatment of ICAD.

Methods A total of 95 patients (79 male; median age 68 years) with 106 intracranial atherosclerotic stenotic lesions underwent endovascular treatment using Coroflex ${ }^{\circledR}$ Please stents (B. Braun, Melsungen, Germany). Location and degree of target stenoses before and after treatment and at follow-up and adverse clinical sequelae of treatment were registered. Post-procedural medication included $100 \mathrm{mg}$ acetylsalicylic acid (ASA) and $75 \mathrm{mg}$ clopidogrel for 1 year. Angiographic follow-up was scheduled for 6, 12, 26 and 52 weeks after the treatment.

Results The lesion locations were as follows: internal carotid artery (ICA) petrous $(n=44,42 \%)$, ICA cavernous $(n=43,41 \%)$, ICA paraclinoid $(n=4,4 \%)$, intradural vertebral artery $(\mathrm{VA} ; \mathrm{n}=11,10 \%)$ and basilar artery $(\mathrm{BA} ; \mathrm{n}=4$,
\end{abstract}

Z. Vajda · M. Aguilar · T. Göhringer · D. Horváth-Rizea ·

H. Henkes $(\bowtie)$

Klinik für Neuroradiologie, Neurozentrum, Klinikum Stuttgart,

Kriegsbergstr. 60, 70174 Stuttgart, Germany

e-mail: hhhenkes@aol.com

H. Bäzner

Klinik für Neurologie, Neurozentrum, Klinikum Stuttgart,

Stuttgart, Germany

H. Henkes

Medizinische Fakultät der Universität Duisburg-Essen,

Essen, Germany
$4 \%$ ). Of the lesions seven could not be treated due to difficult anatomy and stent stiffness ( $7 \%$ technical failure rate). The combined post-interventional neurological morbidity and mortality rate, including stroke, intracerebral hemorrhage (ICH), subarachnoid hemorrhage (SAH) and carotid cavernous fistula (CCF) was $n=4(3.7 \%)$ within and $n=1$ $(0.9 \%)$ at and beyond 30 days, respectively. Angiographic and clinical follow-up examinations were carried out for 78 (78\%) of the lesions (mean 16.1 months, maximum 48 months). Asymptomatic recurrent stenosis was seen in 3 out of $78(3.8 \%)$ lesions and there was 1 case of late stent thrombosis $(0.9 \%)$.

Conclusions Treatment of ICAD using drug-eluting coronary stents is safe and effective but technical failure due to stent stiffness remains a problem. Application of the more flexible, newest generation thin-strut stents, however, shows promising results.

Keywords Atherosclerosis - Intracranial stenosis · Drug-eluting stent $\cdot$ Endovascular $\cdot$ Stroke $\cdot$

Transitory ischemic attack

\section{Introduction}

Intracranial atherosclerotic stenoses are responsible for at least $8-10 \%$ of ischemic strokes [1]. The warfarin-aspirin symptomatic intracranial disease study (WASID, [2]) and the extracranial-intracranial bypass study [3] demonstrated suboptimal results for the medical or unselected surgical management of these lesions. Early endovascular attempts with balloon dilatation alone did not gain widespread adoption due to issues of vessel dissection and early elastic recoiling [4-6] but these issues can be overcome by the application of stents. The options for stent treatment in intra- 
cranial stenotic lesions include primary stenting by implantation of a balloon-mounted bare metal [7] and drug-eluting stents (DES; [8-12]) designed originally for the coronary vasculature or dedicated for neurovascular application [13] or secondary implantation of a slightly oversized selfexpanding stent following a moderately undersized balloon dilatation [14]. Despite continuously growing experience in patient selection, procedural feasibility, safety and the durability of revascularization, high rates (24-31\%) of recurrent stenosis still remain the main drawback of intracranial stenting $[15,16]$. Achieving lower recurrence rates following intracranial stenting is therefore of major importance, although promising results of effective re-treatment of recurrent in-stent stenotic lesions have been shown recently by dilatation using a drug-eluting balloon $[17,18]$.

The application of sirolimus or paclitaxel eluting balloon mounted coronary stents has already been shown to be a feasible, efficient and cost-effective treatment of intracranial stenotic lesions [8-12]. The experience is, however, still rather limited with a total of 82 published cases to the best of our knowledge, performed in several centers applying a variety of stents and treatment protocols.

This article presents data on the procedural safety, efficacy and mid-term patency rates from a retrospective series of stent treatment of 106 intracranial atherosclerotic stenotic lesions, performed in a single institution under a standardized periprocedural and postprocedural protocol and patient management, using the same type of drug-eluting stent.

\section{Materials and Methods}

\section{Patient Selection}

The present series comprised 95 consecutive patients who underwent elective endovascular treatment of 106 significant $(\geq 50 \%)$ intracranial atherosclerotic arterial stenoses in the period from March 2007 to August 2011 in a single institution by or under the supervision of the senior author, according to identical principles of the entire procedural management.

Endovascular treatment using the Coroflex ${ }^{\circledR}$ Please (B. Braun, Melsungen, Germany) stent was offered to patients with an intracranial stenotic lesion, if the lumen loss at the stenotic vessel segment was $\geq 50 \%$ and this stenosis was either symptomatic, progressive or accompanied by other stenoses. Previous failure of medical treatment was not considered a compulsory criterion.

Stenotic lesions located on the intradural internal carotid artery (ICA), the intradural vertebral artery (VA) and the trunk of the basilar artery (BA) were included in the study.

Patients were selected for the treatment of stenosis with a DES on the basis of anatomical criteria. Arguments in favor for the use of a DES were straight proximal vessels without excessive atherosclerotic tortuosity, no major caliber differences of the target vessel proximal and distal to the stenotic segment and a distal vasculature allowing for a sufficiently distant insertion of the microguidewire. In addition to formal criteria, the anticipated ease or difficulty of the access to a given intracranial stenosis with a relatively rigid stent was also considered. The extradural or intradural location of the target stenosis per se was of no relevance for this decision-making.

All patients were explicitly advised about the off-label intracranial use of the drug-eluting coronary stent. (Comment: In German jurisdiction, off-label use of medical devices is exempt from prosecution, if the patient has a serious, e.g. potentially life-threatening disorder, there is no reasonable or only a less favorable therapeutic alternative, available scientific data justify the expectation that with this device a better if not successful outcome could be achieved and the patient or legal representative is informed about the off-label character as well as about the procedural risks and potential treatment alternatives.)

Treatment was considered indicated if the target stenosis was symptomatic or progressive during follow-up or if the affected vessel had no sufficient collaterals or if a stenosis of the contralateral vessel has been symptomatic. These circumstances are considered to carry an increased risk of subsequent cerebral ischemia.

\section{Procedures}

The periprocedural management included a neurological examination by an independent neurologist prior to and after the endovascular treatment, brain magnetic resonance imaging/magnetic resonance angiography (MRI/MRA) and the administration of dual medical platelet anti-aggregation therapy. A loading dose of $500 \mathrm{mg}$ acetylsalicylic acid (ASA) and $600 \mathrm{mg}$ clopidogrel was given at least 1 day prior to treatment followed by $100 \mathrm{mg}$ ASA and $75 \mathrm{mg}$ clopidogrel daily for at least 1 year and $100 \mathrm{mg}$ ASA daily thereafter. All endovascular procedures were carried out with the patient under general anesthesia via a $6 \mathrm{~F}$ or $8 \mathrm{~F}$ guiding catheter. During the procedure, standard medication included $5000 \mathrm{U}$ heparin i.v., $500 \mathrm{mg}$ ASA i.v. and $2 \mathrm{mg}$ glycerine trinitrate intra-arterially (i.a.) for prevention of mechanically induced vasospasm. The target stenosis was visualized without other over-projecting vessels and with the least possible foreshortening. The normal vessel diameter adjacent to the stenosis and the diameter and length of the stenosis were determined using the calibrated measurement program of the Axiom Artis digital subtraction angiography (DSA) system (Siemens, Erlangen, Germany). Under a single road map the vessel distal to the stenosis was catheterized with a Silverspeed (ev3, Irvine, CA, USA) or Traxcess14 (Terumo, Somerset, NJ, USA) microguidewire. The diameter of the Coroflex ${ }^{\circledR}$ 
Please stent was selected to reach about $80 \%$ of the diameter of the normal vessel. The stents were implanted at nominal pressure $(10 \mathrm{~atm})$ with a manometer. After deflation and withdrawal of the balloon catheter a final DSA run was carried out to confirm the result and to exclude complications. During the first days after the procedure all possible efforts were undertaken to maintain the systolic blood pressure at $\leq 130 \mathrm{mmHg}$. Prior to discharge all patients underwent MRI as well as a clinical examination. Angiographic follow-up was scheduled for 6 and 12 weeks, 6 and 12 months and yearly thereafter. The follow-up angiography included DSA runs with projections and magnifications equivalent to those used for the original treatment. On these occasions patients were clinically examined and interviewed specifically for intermittent ischemic events.

\section{Results}

A total of 95 patients (median age 68 years, age range 44 84 years, male-to-female ratio 79/16) with 106 intracranial atherosclerotic lesions were treated. The lesions were located as follows: ICA petrous $(\mathrm{n}=44,42 \%)$, ICA cavernous $(n=43,41 \%)$, ICA paraclinoid $(n=4,4 \%)$, intradural VA $(n=11,10 \%)$ and BA $(n=4,4 \%)$. The distribution of the lesions within the intradural and extradural segments was $19(18 \%)$ and $87(82 \%)$, respectively.

Of the 106 intracranial lesions 14 (13\%) were asymptomatic, $65(61 \%)$ were symptomatic with transient ischemic attacks (TIA), stroke or silent infarcts in the area of the affected vessel and $27(25 \%)$ lesions were treated in the setting of multivessel disease. Multivessel disease was defined as stenotic lesion of the intracranial ICA or VA with occlusion, hypoplasia or high-grade stenosis of the corresponding contralateral vessel or segments of the circle of Willis, e.g. missing A1 segment of the contralateral anterior cerebral artery (ACA) or missing/hypoplastic P1 segment of the ipsilateral posterior cerebral artery (PCA).

The severity of the stenosis was $50-69 \%$ in $80(75 \%)$ and $70-95 \%$ in $26(25 \%)$ of the lesions. The average degree of target stenoses was determined as $64.9 \pm 1 \%$ before and $16.4 \pm 1 \%$ after the treatment. A summary of lesion characteristics is given in Table 1 .

In seven lesions $(7 \%)$ the Coroflex ${ }^{\circledR}$ Please stent could not be advanced into the stenotic segment due to an extremely elongated supra-aortic vascular anatomy, an elongated and calcified carotid siphon or due to the stiffness of the shaft tip or the stent itself. The treatment of these lesions was completed using either a more flexible bare metal coronary stent (Coroflex ${ }^{\circledR}$ Blue Ultra, B. Braun, Melsungen, Germany) or by undersized balloon dilatation followed by the implantation of a self-expanding nitinol stent (Enterprise, Codman, New Brunswick, NJ, USA).
Table 1 Lesion distribution and characteristics

\begin{tabular}{llllll}
\hline Lesion location & \multicolumn{2}{l}{$\begin{array}{l}\text { Severity of stenosis } \\
50-70 \% />70 \%\end{array}$} & & \multicolumn{2}{l}{$\begin{array}{l}\text { Asymptomatic/sympto- } \\
\text { matic/multivessel disease }\end{array}$} \\
\cline { 2 - 3 } \cline { 5 - 6 } & $\mathrm{n}$ & $\%$ & & $\mathrm{n}$ & $\%$ \\
\hline ICA petrous & $29 / 15$ & $66 / 34$ & & $8 / 23 / 13$ & $18 / 52 / 30$ \\
ICA cavernous & $36 / 7$ & $84 / 16$ & & $5 / 26 / 12$ & $12 / 60 / 28$ \\
ICA paraclinoid & $4 / 0$ & $100 / 0$ & & $1 / 2 / 1$ & $25 / 50 / 25$ \\
VA/V4 & $8 / 3$ & $73 / 27$ & & $0 / 10 / 1$ & $0 / 91 / 9$ \\
BA & $3 / 1$ & $75 / 25$ & & $0 / 4 / 0$ & $0 / 100 / 0$ \\
Total & $80 / 26$ & $75 / 25$ & & $14 / 65 / 27$ & $13 / 61 / 26$ \\
\hline
\end{tabular}

$B A$ basilar artery, $I C A$ internal carotid artery, $V A$ vertebral artery

Technical success, defined as less than $50 \%$ residual stenosis at the end of the procedure, was achieved in all of the cases where the Coroflex ${ }^{\circledR}$ Please stent could be implanted $(\mathrm{n}=99,100 \%$; Fig. 1).

Of the procedures where the Coroflex ${ }^{\circledR}$ Please stent could be implanted, $94(94.9 \%)$ were completed without any complication. A direct carotido-cavernous sinus fistula was encountered during the treatment of three stenotic lesions $(2.8 \%)$ of the cavernous ICA (two of these lesions were symptomatic with TIAs) as major complication, requiring further endovascular treatment. No permanent neurological deficit resulted from these dissections. The fourth adverse event was a large hemodynamic infarction of the contralateral hemisphere following the treatment of a high-grade stenotic lesion of the right cavernous ICA and chronic occlusion of the left ICA. Due to extreme tortuosity of the supra-aortic vessels, direct access was established by direct puncture of the cervical right CCA. There were no signs of complication during the interventional procedure itself. At the end of the procedure the patient was transferred to the operating room (OR) and the introducer sheet was removed surgically. Following extubation the patient developed high grade hemiparesis on the right side [modified Rankin Scale (mRS) grade 4] with territorial infarcts without significant improvement during the 4-month follow-up period, resulting in a procedure related neurological morbidity beyond 30 days of $0.9 \%$. There was one case $(0.9 \%)$ of asymptomatic dissection of the stented segment without any clinical relevance. Vasospasm requiring treatment was not encountered. Thus the combined procedure-related neurological morbidity and mortality rate, including stroke, intracerebral hemorrhage ( $\mathrm{ICH})$, subarachnoid hemorrhage (SAH) and carotid cavernous fistula (CCF) was 4/106 (3.8\%) within 30 days and $1 / 106(0.9 \%)$ at 30 days and beyond, respectively.

Angiographic and clinical follow-up examinations were obtained in $78(78 \%)$ of the lesions. The average follow-up period was 16.1 months and the longest follow-up period was 48 months.

Recurrent stenosis, defined as an in-stent stenotic lesion of more than $50 \%$ lumen diameter reduction on the follow- 

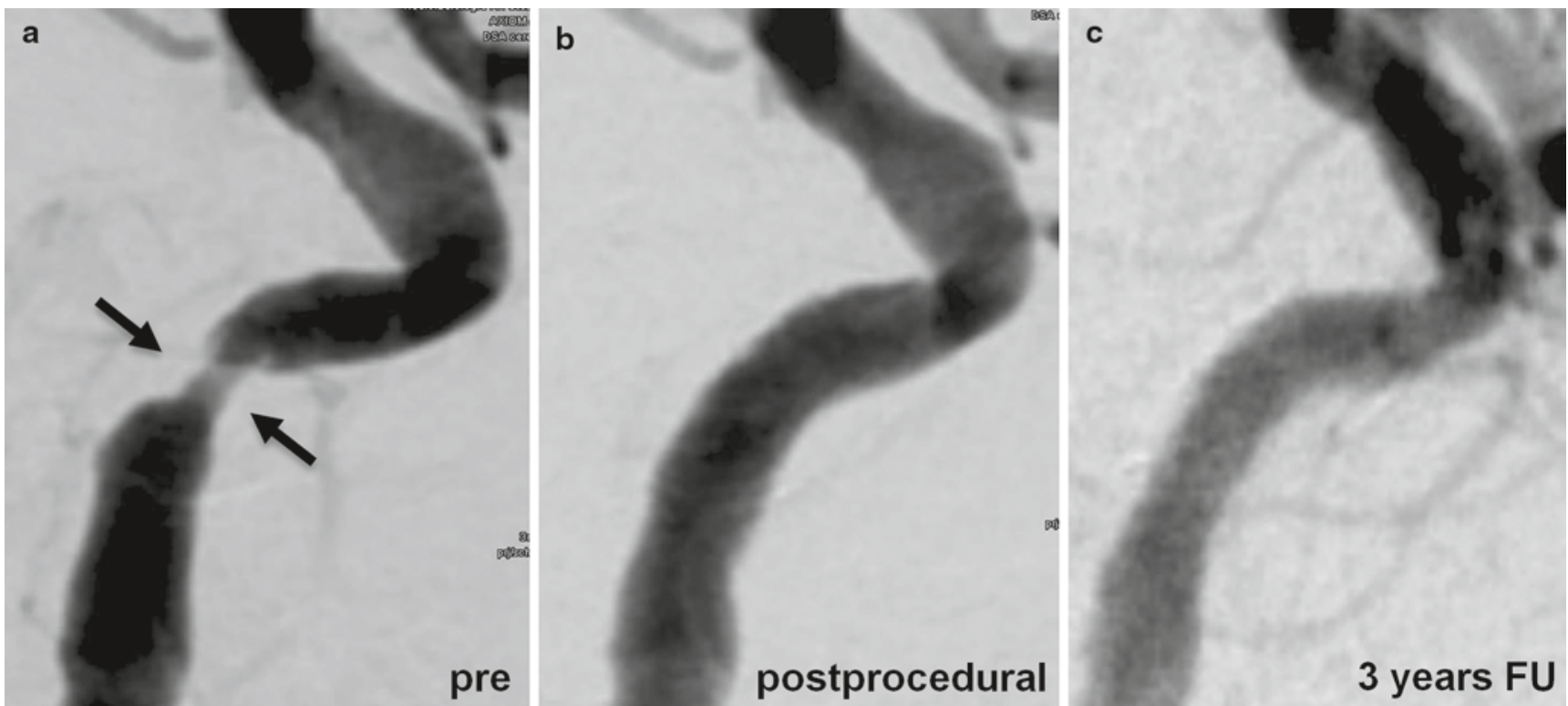

Fig. 1 Preprocedural (a), postprocedural (b) and 3-year follow-up digital subtraction angiography (c) of a symptomatic, high-grade stenotic lesion of the left internal carotid artery in a 71-year-old female patient, treated by Coroflex ${ }^{\circledR}$ Please DES deployment.

up DSA series, was seen in 3 out of 78 (3.8\%) lesions after 190, 224 and 233 days, respectively. All of these recurrent lesions were located in the intracranial ICA and were asymptomatic (Fig. 2). One case of late stent thrombosis (0.9\%) occurred 3 months after the DES implantation in the cavernous segment of the left ICA in a 60 -year-old male patient. The first DSA follow-up examination in this patient, 6 weeks after the stent implantation showed full patency of the stented segment without any sign of a recurrent lesion. The patient suffered from concomitant cardiac arrest with a poor clinical outcome.

Stent migration was not observed.

\section{Discussion}

Atherosclerotic stenotic lesions of the intracranial arteries account for $8-10 \%$ of ischemic strokes [19]. The efficacy of medical and surgical treatment options for intracranial atherosclerotic disease (ICAD) is suboptimal: the WASID study showed that in patients on best medical care, symptomatic intracranial disease carried at least a $9-12 \%$ annual risk of major stroke or death [2], whereas the extracranial-intracranial bypass study demonstrated more frequent and earlier occurrence of both nonfatal and fatal stroke following the creation of an extracranial-intracranial (EC-IC) bypass, despite the impressive postoperative bypass patency rate of $96 \%$ [3]. The above mentioned issues sparked the interest in the endovascular treatment options of ICAD. The experience with balloon angioplasty alone without stent implantation is limited and results are rather unconvincing with weaknesses, such as elastic recoil and dissection $[5,6]$. The application of balloon-mounted or self-expandable bare metal stents is an established treatment option for ICAD, although procedural safety and recurrent lesions remain a concern [15]. The National Institute of Neurological Disorders and Stroke (NINDS) has recently stopped patient enrollment in the Stenting vs. Aggressive Medical Management for Preventing Recurrent Stroke in Intracranial Stenosis (SAMMPRIS) study, which is the first prospective randomized multicenter trial with 50 participating centers in North America, evaluating whether intracranial angioplasty combined with stenting adds benefit to aggressive medical therapy alone for preventing stroke in patients with symptomatic intracranial arterial stenosis [20]. The reason for the premature halt was the high periprocedural complication rate with a $14 \%$ rate of stroke or death in patients treated with angioplasty and stenting within the first 30 days, compared with $5.8 \%$ of patients treated with medical therapy alone, whereas beyond 30 days, the rates of stroke in the territory of the stenotic artery were similar in the 2 groups [21].

High rates of in-stent restenotic (ISR) lesions are also problematic: case series of stent treatment for ICAD using bare metal stents reported hemodynamically significant ISR rates from $13.8-37 \%$ using bare metal coronary stents $[15$, $16]$ and from $24.7-31 \%$ using self-expanding nitinol stents $[22,23]$.

The efficacy of DESs in reducing neointimal hyperplasia, late luminal loss and angiographic restenosis over bare metal stents in the coronary vasculature has been extensively studied and demonstrated in randomized trials [24]. Reports on the application of DESs in the treatment of neurovascular 

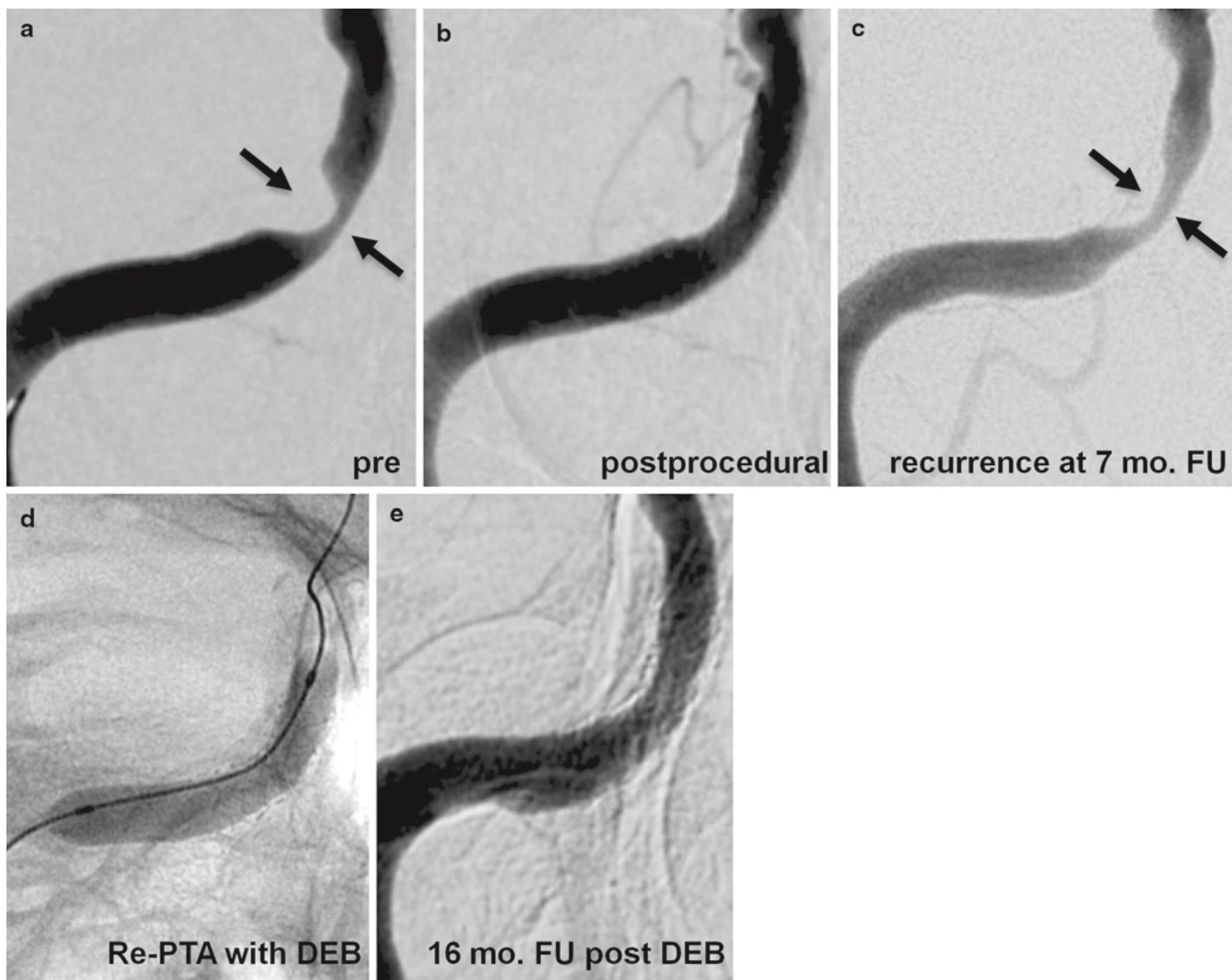

Fig. 2 Development of a recurrent in-stent stenotic lesion in a 71year-old male patient with a symptomatic, high-grade stenosis of the petrous segment of the right internal carotid artery. The postprocedural digital subtraction angiography image shows an excellent result after the deployment of a Coroflex ${ }^{\circledR}$ Please DES (b), the 7-month follow-up

stenoses are, however, sparse, with to our knowledge only 82 reported cases to date. The procedural and ISR results with coronary DES treatment in ICAD published so far are summarized in Table 2.

The results of this study with $3.8 \%$ recurrence and $0.9 \%$ stent occlusion rate at $78 \%$ DSA follow-up rate with more than 1 year average follow-up period are very promising. The very low periprocedural complication rate $(0.9 \%$ procedure-related morbidity and mortality at and beyond 30 days) is also encouraging, especially in the mirror of the recently published result of the SAMMPRIS trial [27], where the poor results in the endovascular arm were mainly attributable to complications of the angioplasty and stenting procedure. It is a matter of debate whether these complications are due to device issues, limited experience and skills of examination, however revealed an asymptomatic, high-grade in-stent recurrent lesion as a result of intimal hyperplasia (c). Percutaneous transluminal angioplasty of the recurrent lesion was performed using a drug-eluting (paclitaxel) balloon (Sequent Please, B. Braun; d) with very good long-term result (e)

the certified operators, poor patient selection, flaws of the trial concept or a combination thereof, which is most likely. Apart from the specific features of the device, proper patient selection is crucial in the endovascular treatment of intracranial stenoses. Patients with high-grade intracranial stenoses who have failed several attempts or regimens of medical treatment are frequently hemodynamically exhausted and therefore prone to postprocedural stroke and reperfusion hemorrhage. Given the low complication rate of intracranial angioplasty and stenting there should be more concern for treating patients too late than unnecessarily early.

Dissection of the cavernous ICA segment is unrelated to the flexibility of the balloon or stent. In some patients cavernous ICA stenoses are so calcified and therefore hard and the cavernous segment is in the same moment so fragile that 
Table 2 Review of previous studies on intracranial stenting with drug-eluting stents

\begin{tabular}{|c|c|c|c|c|c|c|c|c|c|c|c|c|}
\hline \multirow[t]{2}{*}{ Author } & \multirow{2}{*}{$\begin{array}{l}\text { No. of } \\
\text { lesions } \\
\text { attemp- } \\
\text { ted to } \\
\text { treat }\end{array}$} & \multirow{2}{*}{$\begin{array}{l}\text { Treated } \\
\text { intradural/ } \\
\text { extradural } \\
\text { lesions } \\
(\%)\end{array}$} & \multicolumn{2}{|c|}{$\begin{array}{l}\text { Stenosis degree } \\
(\%)\end{array}$} & \multirow[t]{2}{*}{$\begin{array}{l}\text { Stent } \\
\text { type }\end{array}$} & \multirow{2}{*}{$\begin{array}{l}\text { Failed } \\
\text { at- } \\
\text { tempts } \\
(\%)\end{array}$} & \multirow{2}{*}{$\begin{array}{l}\text { Ad- } \\
\text { verse } \\
\text { events } \\
(\%)\end{array}$} & \multirow{2}{*}{$\begin{array}{l}\text { Procedure } \\
\text { related mor- } \\
\text { bidity/mor- } \\
\text { tality at } 30 \\
\text { days }(\%)\end{array}$} & \multirow{2}{*}{$\begin{array}{l}\text { Lesions } \\
\text { with } \\
\text { DSA } \\
\text { follow- } \\
\text { up (\%) }\end{array}$} & \multirow{2}{*}{$\begin{array}{l}\text { Average } \\
\text { DSA } \\
\text { follow- } \\
\text { up time } \\
\text { (months) }\end{array}$} & \multirow{2}{*}{$\begin{array}{l}\text { Recurrence } \\
\text { on DSA } \\
(\%)\end{array}$} & \multirow{2}{*}{$\begin{array}{l}\text { Stent } \\
\text { occlusion } \\
(\%)\end{array}$} \\
\hline & & & $\begin{array}{l}\text { Pretre- } \\
\text { atment }\end{array}$ & $\begin{array}{l}\text { Posttre- } \\
\text { atment }\end{array}$ & & & & & & & & \\
\hline $\begin{array}{l}\text { Abou-Chebl } \\
\text { et al. [8] }\end{array}$ & 8 & $62 / 38$ & 84 & 2 & $\begin{array}{l}\text { Cypher, } \\
\text { Taxus }\end{array}$ & 0 & 25 & 0 & 63 & 11 & 0 & 0 \\
\hline $\begin{array}{l}\text { Gupta } \\
\text { et al. [9] }\end{array}$ & 29 & $\mathrm{n} / \mathrm{a}$ & $\mathrm{n} / \mathrm{a}$ & $\mathrm{n} / \mathrm{a}$ & $\begin{array}{l}\text { Cypher, } \\
\text { Taxus }\end{array}$ & 10 & 12 & 3 & 76 & $\mathrm{n} / \mathrm{a}$ & 5 & 5 \\
\hline $\begin{array}{l}\text { Qureshi } \\
\text { et al. [10] }\end{array}$ & 21 & $72 / 28$ & 68 & 14 & $\begin{array}{l}\text { Cypher, } \\
\text { Taxus }\end{array}$ & 14 & 22 & 5 & 38 & 6 & 14 & 5 \\
\hline $\begin{array}{l}\text { Miao } \\
\text { et al. [11] }\end{array}$ & 11 & $100 / 0$ & $\mathrm{n} / \mathrm{a}$ & $\mathrm{n} / \mathrm{a}$ & $\begin{array}{l}\text { Cypher, } \\
\text { Firebird }\end{array}$ & $\mathrm{n} / \mathrm{a}$ & $\mathrm{n} / \mathrm{a}$ & $\mathrm{n} / \mathrm{a}$ & $\mathrm{n} / \mathrm{a}$ & $\mathrm{n} / \mathrm{a}$ & 9 & 0 \\
\hline $\begin{array}{l}\text { Fields } \\
\text { et al. [12] }\end{array}$ & 13 & $\mathrm{n} / \mathrm{a}$ & 80 & 2 & $\begin{array}{l}\text { Cypher, } \\
\text { Taxus }\end{array}$ & 0 & 0 & 18 & 73 & 8 & 38 & 0 \\
\hline This study & 106 & $18 / 82$ & 65 & 16 & $\begin{array}{l}\text { Coroflex } \\
\text { Please }\end{array}$ & 4.7 & 3.8 & 0.9 & 78 & 12.5 & 3.9 & 0.9 \\
\hline
\end{tabular}

$D S A$ digital subtraction angiography, $n / a$ not available

there is a very thin line between dilatation and dissection of the vessel. These dissections occur with every method and are a part of the risk profile of these lesions and their treatment. The relative stiffness of coronary DESs is related to access issues but not necessarily to safety concerns.

The main drawback of the application of DESs in ICAD seems to be the high rate $(7 \%)$ of failed attempts, which theoretically gets even worse considering the fact that patients in whom difficult supra-aortic anatomy or stenosis morphology were already known were not even attempted to be included in this cohort. The reason behind the high rate of procedural failure is the stiffness of the stent system of the early generations of coronary DESs such as the Coroflex ${ }^{\circledR}$ Please. Newer generation DESs are far more flexible, mainly as a result of the substantially reduced strut thickness. Coroflex ${ }^{\circledR}$ Please features $120 \mu$ thick struts, whereas third generation DES systems, such as Element (Boston Scientific) or Xience (Abbott, Abbott Park, IL, USA) are made of $81 \mu$ thick struts, substantially improving stent navigability (unpublished personal observation). The clinical practice was started when the Coroflex ${ }^{\circledR}$ Please was the latest stent. It is expected that newer generation DESs will combine the low recurrence rate with an improved maneuverability, making selected middle cerebral artery (MCA) and BA stenotic lesions also accessible.

Recently, the superiority of everolimus-eluting stents over paclitaxel-eluting stents with respect to lesion recurrence and clinical endpoints has been established in the cardiology literature with in-stent restenosis rates of $2.3 \%$ versus $5.7 \%$, respectively $[25,26]$. The application of the newest generation, thin-strut DES systems (Element, Xience) with everolimus as the eluted drug for the treatment of ICAD may further improve the already encouraging recurrence rate.
The data presented here are limited in their scientific value in several aspects. There was no direct comparison with any other treatment method or device, e.g. medical treatment alone or bare metal stent (BMS) procedures. Data from primarily clinical series are certainly more prone to inconsistencies than those from a strictly regulated and externally monitored trial. Patient selection was based on the experience and discretion of the senior author, which introduces a certain level of individual or at least institutional decision-making. The data were collected in a single high volume center. Team experience and well-organized infrastructure are factors that contribute largely to the safety of a complex procedure such as intracranial angioplasty and stenting but are more or less independent from the specific device under evaluation. Therefore results achieved with a certain device or method may or may not be generally applicable to other operators and institutions.

In conclusion, the application of drug-eluting coronary stents for intracranial atherosclerotic disease is a safe and effective treatment option with low recurrence rates. Issues of lesion accessibility in difficult anatomical situations remain a problem, early experience with the application of the more flexible, newest generation thin-strut DES systems, however, shows promising results.

Conflict of Interest The authors declare that there is no current or potential conflict of interest in relation to this article. Open Access was sponsored by B. Braun, Melsungen, Germany.

Open Access This article is distributed under the terms of the Creative Commons Attribution Noncommercial License which permits any noncommercial use, distribution, and reproduction in any medium, provided the original author(s) and source are credited. 


\section{References}

1. Levy EI, Turk AS, Albuquerque FC, Niemann DB, Aagaard-Kienitz B, Pride L, et al. Wingspan in-stent restenosis and thrombosis: incidence, clinical presentation, and management. Neurosurgery. 2007;61:644-50.

2. Chimowitz MI, Lynn MJ, Howlett-Smith H, Stern BJ, Hertzberg VS, Frankel MR, et al. Warfarin-aspirin symptomatic intracranial disease trial investigators. Comparison of warfarin and aspirin for symptomatic intracranial arterial stenosis. N Engl J Med. 2005;352:1305-16.

3. Failure of extracranial-intracranial arterial bypass to reduce the risk of ischemic stroke. Results of an international randomized trial. The EC/IC Bypass Study Group. N Engl J Med. 1985;313:1191-1200.

4. Sundt TM Jr, Smith HC, Campbell JK, Vlietstra RE, Cucchiara RF, Stanson AW. Transluminal angioplasty for basilar artery stenosis. Mayo Clin Proc. 1980;55:673-80.

5. Marks MP, Wojak JC, Al-Ali F, Jayaraman M, Marcellus ML, Connors JJ, et al. Angioplasty for symptomatic intracranial stenosis: clinical outcome. Stroke. 2006;37:1016-20.

6. Berg-Dammer E, Henkes H, Weber W, Berlit P, Kuhne D. Percutaneous transluminal angioplasty of intracranial artery stenosis: clinical results in 24 patients. Neurosurg Focus. 1998;5:e13.

7. Vajda Z, Miloslavski E, Güthe T, Schmid E, Schul C, Albes G, et al. Treatment of intracranial atherosclerotic arterial stenoses with a balloon-expandable cobalt chromium stent (Coroflex Blue): procedural safety, efficacy, and midterm patency. Neuroradiology. 2010;52:645-51.

8. Abou-Chebl A, Bashir Q, Yadav JS. Drug-eluting stents for the treatment of intracranial atherosclerosis: initial experience and midterm angiographic follow-up. Stroke. 2005;36:165-8.

9. Gupta R, Al-Ali F, Thomas AJ, Horowitz MB, Barrow T, Vora NA, et al. Safety, feasibility, and short-term follow-up of drugeluting stent placement in the intracranial and extracranial circulation. Stroke. 2006;37:2562-6.

10. Qureshi AI, Kirmani JF, Hussein HM, Harris-Lane P, Divani AA, Suri MF, et al. Early and intermediate-term outcomes with drugeluting stents in high-risk patients with symptomatic intracranial stenosis. Neurosurgery. 2006;59:1044-51.

11. Miao ZR, Feng L, Li S, Zhu F, Ji X, Jiao L, et al. Treatment of symptomatic middle cerebral artery stenosis with balloon-mounted stents: long-term follow-up at a single center. Neurosurgery. 2009;64:79-84.

12. Fields JD, Petersen BD, Lutsep HL, Nesbit GM, Liu KC, Dogan A, et al. Drug eluting stents for symptomatic intracranial and vertebral artery stenosis. Interv Neuroradiol. 2011;17:241-7.

13. Mocco J, Darkhabani Z, Levy EI. Pharos neurovascular intracranial stent: elective use for a symptomatic stenosis refractory to medical therapy. Catheter Cardiovasc Interv. 2009;74:642-6.
14. Henkes H, Miloslavski E, Lowens S, Reinartz J, Liebig T, Kühne D. Treatment of intracranial atherosclerotic stenoses with balloon dilatation and self-expanding stent deployment (WingSpan). Neuroradiology. 2005;47:222-8.

15. Gröschel K, Schnaudigel S, Pilgram SM, Wasser K, Kastrup A. A systematic review on outcome after stenting for intracranial atherosclerosis. Stroke. 2009;40:340-7.

16. Schumacher HC, Meyers PM, Higashida RT, Derdeyn CP, Lavine $\mathrm{SD}$, Nesbit GM, et al. Reporting standards for angioplasty and stent-assisted angioplasty for intracranial atherosclerosis. Stroke. 2009;40:348-65.

17. Güthe T, Miloslavski E, Vajda Z, Peters J, Bäzner H, Henkes H. Recurrent in-stent restenosis in a symptomatic nonatherosclerotic M1 plaque: successful treatment with paclitaxel-eluting balloon dilatation after repeated failure of conventional balloon reangioplasty. Clin Neuroradiol. 2010;20:165-9.

18. Vajda Z, Güthe T, Aguilar M, Heuschmid A, Schmid E, Bäzner E, et al. Neurovascular in-stent stenoses: treatment with conventional and drug-eluting balloons. AJNR Am J Neuroradiol. 2011;32:1942-7.

19. Higashida RT, Meyers PM. Intracranial angioplasty and stenting for cerebral atherosclerosis: new treatments for stroke are needed! Neuroradiology. 2006;48:367-72.

20. Stenting vs. Aggressive Medical Management for Preventing Recurrent Stroke in Intracranial Stenosis (SAMMPRIS). http:// clinicaltrials.gov/ct2/show/NCT00576693. Accessed 17 July 2010.

21. http://www.nlm.nih.gov/databases/alerts/intracranial_arterial_ stenosis.html.

22. Turk AS, Levy EI, Albuquerque FC, Pride GL Jr, Woo H, Welch $\mathrm{BG}$, et al. Influence of patient age and stenosis location on wingspan in-stent restenosis. AJNR Am J Neuroradiol. 2008;29:23-7.

23. Vajda Z, Schmid E, Güthe T, Klötzsch C, Lindner A, Niehaus L, et al. The modified Bose method for the endovascular treatment of intracranial atherosclerotic arterial stenoses using the Enterprise stent. Neurosurgery. 2012;70:91-101.

24. Serruys PW, Kutryk MJ, Ong AT. Coronary-artery stents. N Engl J Med. 2006;354:483-95.

25. Stone GW, Rizvi A, Newman W, Mastali K, Wang JC, Caputo R, et al. Everolimus-eluting versus paclitaxel-eluting stents in coronary artery disease. N Engl J Med. 2010;362:1663-74.

26. Stone GW, Midei M, Newman W, Sanz M, Hermiller JB, Williams J, et al. Comparison of an everolimus-eluting stent and a paclitaxel-eluting stent in patients with coronary artery disease: a randomized trial. JAMA. 2008;299:1903-13.

27. Chimowitz MI, Lynn MJ, Derdeyn CP, Turan TN, Fiorella D, Lane BF, et al. Stenting versus aggressive medical therapy for intracranial arterial stenosis. N Engl J Med. 2011;365:993-1003. 